\title{
К ВОПРОСУ О ПРИМЕНИМОМ ПРАВЕ ВО ВНЕШНЕЭКОНОМИЧЕСКИХ ДОГОВОРАХ
}

\section{THE ISSUE OF APPLICABLE LAW IN FOREIGN ECONOMIC CONTRACTS}

\section{N. Belova}

Summary. In the presented article, the author had considered the issue of choosing the applicable law when concluding a foreign economic contract. Based on the legal norms stated in Article 1210 of Section IV of Part 3 of the Civil Code of the Russian Federation, the materials of judicial practice, various options for concluding an agreement on the applicable law were analyzed both at the stage of negotiating the contractual terms and subsequently during the execution of the contract.

Keywords: autonomy of will, applicable law, agreement on applicable law, foreign economic contract, private international law.

\author{
Белова Наталья Юрьевна \\ ФГОБУ ВО «Финансовый университет при \\ Правительстве Российской Федерации», Москва \\ belova.natalia23@mail.ru
}

Аннотация. В представленной статье автором рассмотрен вопрос выбора применимого права при заключении внешнеэкономического договора. На основе правовых норм, закрепленных в статье 1210 раздела IV части 3 Гражданского кодекса Российской Федерации, материалов судебной практики проанализированы различные варианты заключения соглашения о применимом праве как на стадии согласования договорных условий, так и впоследствии при исполнении контракта.

Ключевые слова: автономия воли, применимое право, соглашение о применимом праве, внешнеэкономический договор, международное частное право.

Согласно статье 1186 Гражданского кодекса Российской Федерации (далее - ГК РФ) право, подлежащее применению к гражданско-правовым отношениям с участием иностранных граждан или иностранных юридических лиц либо гражданско-правовым отношениям, осложненным иным иностранным элементом, в том числе в случаях, когда объект гражданских прав находится за границей, определяется на основании международных договоров РФ, настоящего Кодекса, других законов (пункт 2 статьи 3) и обычаев, признаваемых в РФ [1].

В статье 1210 ГК РФ закреплено право сторон с участием иностранных контрагентов самостоятельно выбирать применимое право к регулированию договорных отношений. Таким образом, речь идёт о практической реализации автономии воли участников договорных правоотношений, осложнённых иностранным элементом. Приведенное положение закона следует рассматривать как одну из наиболее значимых коллизионных норм, содержащихся в разделе IV части 3 ГК РФ и принятых к применению в международном частном праве. Как указал Международный коммерческий арбитраж при Торгово-промышленной палате Российской Федерации (далее - МКАС при ТПП) принцип автономии воли предполагает не только допустимость выбора сторонами применимого права, но также их возможность полностью либо частично изменить и прекратить ранее достигнутое соглашение о выборе права [2]. 
Президиум Высшего арбитражного суда РФ в пункте 6 своего информационного письма от 16 февраля 1998 г. № 29 «Обзор судебно-арбитражной практики разрешения споров по делам иностранных лиц» отметил, что «при разрешении спора, вытекающего из внешнеэкономической сделки, в отношении которой стороны определили применимое право, арбитражный суд исходит из того, что стороны свободны в выборе права, применимого к существу спора (принцип автономии воли сторон). При этом включение в контракт условия о применимом праве означает, что стороны принимают на себя обязательство руководствоваться в своих отношениях нормами данного права» [3].

В международном частном праве субъекты правовых отношений при заключении договора могут определять применимое право, как непосредственно при подписании договора, так и в дальнейшем при его исполнении, и даже на стадии претензионного или судебного разбирательства.

Категорию «применимое право» следует толковать широко, включая в неё нормы национального права, нормы международного права, нормы международных договоров, а также в определенных случаях общие принципы права, обычаи и обыкновения международной торговли [4]. Но согласно положениям ГК РФ, возможность выбора применимого право принадлежит сторонам внешнеэкономического договора. Это может быть материальное право одного из участников договорных отношений, которое прямо закреплено в тексте международного контракта (например, правом, регулирующим настоящий контракт, является материальное право РФ, материальное право Республики Беларусь; договор регулируется законодательством Федеративной Республики Германия и т.д.), либо сторонами предусматривается альтернативный способ выбора применимого права путем указания в качестве такового права государства стороны, которая при возникновении спора в будущем выступит истцом либо ответчиком (например, правом, регулирующим настоящий контракт, является материальное право страны истца). В качестве применимого права участники внешнеэкономического контракта могут выбрать нейтральное право, то есть право третьей стороны- любого иностранного государства, не связанного со стороной договора (например, российская и немецкая компании при заключении договора в качестве применимого права выбрали материальное право Франции). Допускается использование сторонами внешнеэкономического контракта в качестве применимого права также положений международных договоров, неформальных сводов правил, обычаев международной торговли (например, Правила Международной торговой палаты для использования национальных и международных торговых терминов ИНКОТЕРМС 2020
(INCOTERMS2020), Принципы международных коммерческих договоров (Принципы УНИДРУА), Конвенция о праве, применимом к международной купле-продаже товаров и т.д.). Позволим заметить, что международным торговым обычаям придают весьма большое значение при регулировании договорных отношений во внешнеэкономической деятельности. Необходимо отметить, что ВС РФ в своем Постановлении от 09.07.2019 № 24 «О применении норм международного частного права судами Российской Федерации» четко указал, что так называемые источники мягкого права могут быть использованы в качестве применимого права для регулирования договорных отношений, только при условии наличия прямо выраженного соглашения сторон [5]. Вместе с тем в практической деятельности компаний можно встретить и обратную ситуацию, когда стороны внешнеэкономического контракта непосредственно при его заключении закрепляют неприменение норм международных договоров, международных торговых обычаев и т.п. для регулирования их договорных взаимоотношений (например, в тексте внешнеэкономического договора возможно встретить следующую формулировку: настоящий договор не регулируется нормами Конвенции ООН о договорах международной купли-продажи товаров, применение которой настоящим прямо исключается). При этом свобода выбора применимого права никоим образом не связана с конкретными способами рассмотрения договорных споров, возникающих в процессе заключения или исполнения внешнеэкономических договоров. Такие споры могут рассматриваться как государственными судебными органами (арбитражными, хозяйственными и т.п. судами), так и негосударственными судами (третейским судом, международным коммерческим арбитражным судом при Торгово-промышленной палате соответствующего государства и т.д.).

Согласно пункту 2 статьи 1210 ГК РФ соглашение сторон о выборе применимого права должно быть прямо выражено или вытекать из условий или совокупности обстоятельств дела [6]. В соответствии с пунктом 27 Постановления Пленума Верховного Суда РФ от 09.07.2019 № 24 «О применении норм международного частного права судами РФ» в соглашении о применимом праве стороны вправе использовать любые термины и формулировки, указывающие на выбор ими того или иного права (например, указание на применение права, законодательства, законов, нормативных актов или норм определенной страны).

Устанавливая наличие воли сторон, направленной на выбор применимого права, суд вправе констатировать существование подразумеваемого соглашения о применимом праве, в частности, в случае, если стороны в тексте договора ссылались на отдельные гражданско-правовые нормы определенной страны либо если 
стороны при обосновании своих требований и возражений (например, в исковом заявлении и отзыве на него) ссылаются на одно и то же применимое право [7].

В разделе IV части 3 ГК РФ, содержащей нормы международного частного права, отсутствуют специальные требования к форме соглашения сторонами внешнеэкономического договора о применимом праве. В связи с чем, оно может быть включено в качестве одного из условий в текст международного контракта. Стороны внешнеэкономического договора могут подписать отдельный документ, в котором указать применимое право к их гражданским взаимоотношениям. В судебных решениях МКАС при ТПП РФ соглашения о применимом праве признавались совершенными в надлежащей форме в результате обмена письмами, сообщениями по телетайпу, телеграфу либо с использованием иных средств электросвязи, обеспечивающих фиксацию подобного соглашения. Считаются они заключенными и тогда, когда в договоре или корреспонденции сторон, на основании которой договор признается заключенным, имеется ссылка на документ, содержащий условие о праве, подлежащем применению [8]. Необходимо отметить, что заключение сторонами внешнеэкономического договора соглашения о применимом праве не является самостоятельной сделкой с точки зрения гражданского права.

Пункт 3 статьи 1210 Гражданского кодекса РФ позволяет на законодательном уровне сторонам внешнеэкономического контракта разрешить вопрос о подлежащем применению праве и после его заключения. Хозяйствующие субъекты могут выбирать или изменять ранее выбранное применимое право после заключения договора. Подобный выбор участников договорных отношений будет иметь обратную силу и будет считаться действительным с даты заключения контракта.

Однако следует отметить, что в отечественной судебной и арбитражной практике прочно утвердился подход, в соответствии с которым совокупность положений ст. 1210 ГК РФ, как то: п. 1 (признающий выбор права как при заключении договора, так и в последующем) и п. 2. (признающий как прямо выраженные соглашения, так и определённо вытекающие из условий договора либо совокупности обстоятельств дела), допускает изменение соглашения о применимом праве, совершенного в письменной форме (например, в качестве условия договора), последующим соглашением не в той же письменной форме (например, посредством заявление в ходе судебного или арбитражного процесса) [9].

В соответствии с пунктом 4 статьи 1210 ГК РФ сторонами внешнеэкономического договора могут выбрать право, подлежащее применению как в целом к контракту, так и к отдельным его частям. Например, в договоре могут содержаться следующие условия: правом, регулирующим настоящий контракт, является материальное право РФ; вопросы ответственности за неисполнение или ненадлежащее исполнение обязательств по контракту регулируется материальным правом Республики Беларусь. Таким образом, в зависимости от вида спорного правоотношения между участниками внешнеэкономического договора компетентным органом (судом) будет применяться либо право РФ, либо право Республики Беларусь. Подобный выбор сторон договора, осложненного иностранным элементом, следует считать допустим только при условии, что применение права разных государств к отдельным частям внешнеэкономического контракта не приведет к признанию самого договора или отдельных его частей недействительными. Полагаем, что на практике реализация названной нормы может вызвать определенные затруднения, так как правовое регулирование договорных отношений нормами права разных стран может привести к возникновению противоречий между сторонами при толковании договора, при определении прав и обязанностей сторон, при рассмотрении возникающих претензий и т.д. В тех случаях, когда споры, возникшие между сторонами внешнеэкономического контракта, разрешаются в судебном порядке, суду, прежде всего, необходимо выяснить действительные намерения участников договорных отношений по вопросу применимого права. При наличии таких непреодолимых противоречий суд признает соглашение сторон о выборе применимого права неисполнимым и определяет договорный статут на основе коллизионных норм, применимых при отсутствии соглашения сторон о выборе права [10].

В соответствии с пунктом 5 статьи 1210 ГК РФ если в момент выбора сторонами договора, подлежащего применению права все касающиеся существа отношений сторон обстоятельства связаны только с одной страной, выбор сторонами права другой страны не может затрагивать действие императивных норм права той страны, с которой связаны все касающиеся существа отношений сторон обстоятельства [11]. Указанное положение должно учитываться сторонами внешнеэкономического договора при определении применимого права. Например, согласно пункту 2 статьи 1213 ГК РФ применяется российское право к договорам в отношении недвижимого имущества, включая земельные участки, участник недр и т.д.

Автономия воли участников частноправовых отношений, осложненных иностранным элементом, которая позволяет им выбрать применимое право с целью регулирования взаимоотношений, нашла широкое распространение в коллизионном праве многих государств. Например, согласно статье 1112 Гражданского кодекса Республики Казахстан договор регулируется правом 
страны, определенным соглашением сторон, если иное не предусмотрено законодательными актами Республики Казахстан [12]. По аналогии с ГК РФ Гражданский кодекс Республики Казахстан содержит похожие по своему содержанию нормы, определяющие выбор применимого права сторонами внешнеэкономического договора. Выбор применимого права может быть осуществлен участниками внешнеэкономического контракта как при заключении договора, так и при его исполнении в последующем. Также стороны договора, осложнённого иностранным элементом, имеют возможность выбрать применимое право, как для договора в целом, так и для отдельных частей. Как указал в своем интервью профессор Сулейманов М.К. «в соответствии с п. 2 ст. 44 Закона РК от 8 апреля 2016 года «Об арбитраже» при отсутствии соглашения сторон о применимом праве арбитраж определяет применимое право в соответствии с коллизионными нормами, которые он сочтет в данном случае применимыми» [13].

В некоторых государствах допускается ограничение автономии воли при выборе сторонами применимого права. Как указывает Стригунова Д.П. «в праве США ограниченная автономия воли получила закрепление во Втором своде коллизионного права 1971 г. (The Second Restatement on the Conflict of Laws), а также Единообразном торговом кодексе США 1962 г. Restatement 1971 г. хотя и не является источником права, однако обладает значительным авторитетом и на него имеются ссылки в целом ряде судебных решений, выносимых в США. В соответствии с указанными документами выбор права сторонами договора возможен, но только такого, которое связано с договором» [14].

Автономия воли представляет собой способность участников свободно формировать свое волеизъявление при заключении внешнеэкономического договора, в том числе и при определении применимого права. Стороны внешнеэкономического контракта не обязаны согласовывать применимое право. При отсутствии соглашения участников договора, осложненного иностранным элементом, применимое право будет определяться на основе коллизионных норм. Указанный вывод подтверждается и примером из судебной практики. Так Двадцатый арбитражный апелляционный суд в своем постановлении от 25.02.2021 г. № 20АП-7350/2020 по делу № А54-9783/2017 указал, что отсутствие волеизъявления сторон в отношении применимого права означает, что его определяет суд компетентный рассматривать данный спор, руководствуясь при этом применимыми коллизионными нормами международного или национального права [15]. Однако полагаем, что определение применимого права непосредственно сторонами внешнеэкономического контракта позволяет наиболее точно определить границы должного поведения, закрепить права и обязанности участников договорных отношений, а также уменьшить неблагоприятные последствия при рассмотрении взаимных претензий и спорных ситуаций. При этом участники договорных отношений, осложнённых иностранным элементом, должны максимально чётко и однозначно формулировать условия о применимом праве.

\section{ЛИТЕРАТУРА}

1. Гражданский кодекс Российской Федерации (часть третья) от 26.11.2001 № 146-Ф3. // Российская газета. 28.11.2001. № 233.

2. Решение МКАС при ТПП РФ от 18.04.2017 по делу № 102/2016. [Электронный ресурс]. URL: https://gkrfkod.ru/pract/reshenie-mkas-pri-tpp-rf-ot-18042017po-delu-n-1022016/ (дата обращения 15.03.2021г.).

3. Информационное письмо Президиума ВАС РФ от 16.02.1998 № 29 «0бзор судебно — арбитражной практики разрешения споров по делам с участием иностранных лиц». // Вестник ВАС РФ. 1998. № 4.

4. Международное частное право: учебник / В.Н. Борисов, Н.В. Власова, Н.Г. Доронина и др.; отв. ред. Н.И. Марышева. 4-е изд., перераб. и доп. М.: ИЗиСП, КОНТРАКТ, 2018. $848 \mathrm{c}$.

5. Постановление Пленума Верховного Суда РФ от 09.07.2019 № 24 «0 применении норм международного частного права судами Российской Федерации». // Бюллетень Верховного Суда РФ. 2019. № 10.

6. Гражданский кодекс Российской Федерации (часть третья) от 26.11.2001 № 146-Ф3. // Российская газета. 28.11.2001. № 233.

7. Постановление Пленума Верховного Суда РФ от 09.07.2019 № 24 «0 применении норм международного частного права судами Российской Федерации». // Бюллетень Верховного Суда РФ. 2019. № 10.

8. Международное частное право: учебник / В.Н. Борисов, Н.В. Власова, Н.Г. Доронина и др.; отв. ред. Н.И. Марышева. 4-е изд., перераб. и доп. М.: ИЗиСП, KOHTPAKT, 2018. $848 \mathrm{c}$.

9. Новикова Т.В. Правовой режим формы соглашения о применимом праве// Актуальные проблемы российского права. 2020. № 5. С. $208-215$.

10. Постановление Пленума Верховного Суда РФ от 09.07.2019 № 24 «0 применении норм международного частного права судами Российской Федерации». // Бюллетень Верховного Суда РФ. 2019. № 10.

11. Гражданский кодекс Российской Федерации (часть третья) от 26.11.2001 № 146-Ф3. // Российская газета. 28.11.2001. № 233.

12. Граждански кодекс Республики Казахстан (особенная часть) от 01 июля 1999 г. // [Электронный ресурc]. URL: https://online.zakon.kz/document/?doc $\mathrm{id}=1006061 \& d 0 c \_i d 2=1013880 \#$ activate_doc=2\&pos=543;-108\&pos2=5577;-104 (дата обращения 22.03.2021 г.). 
13. Интервью с профессором М.К. Сулейменовым. [Электронный ресурс]. URL: https://pravo.hse.ru/intprilaw/news/442606343.html (дата обращения 22.03.2021 г.).

14. Стригунова Д.П. 0 правовой природе автономии воли сторон в сфере правового регулирования международных коммерческих договоров. // Сборник научных статей III Международной научно-практической конференции «Актуальные проблемы предпринимательского и корпоративного права в России и за рубежом» (25 апреля 2016 года, г. Москва) / Е.А. Абросимова, В.К. Андреев, Л.В. Андреева и др.; под общ. ред. С.Д. Могилевского, М.А. Егоровой. М.: РАНХиГС при Президенте Российской Федерации. Юридический факультет им. М.М. Сперанского Института права и национальной безопасности, Юстицинформ, 2016. 496 с.

15. Постановление Двадцатого арбитражного апелляционного суда от 25.02.2021 г. № 20АП-7350/2020 по делу № А54-9783/2017. // СПС «КонсультантПлюс».

○ Белова Наталья Юрьевна ( belova.natalia23@mail.ru ).

Журнал «Современная наука: актуальные проблемы теории и практики»

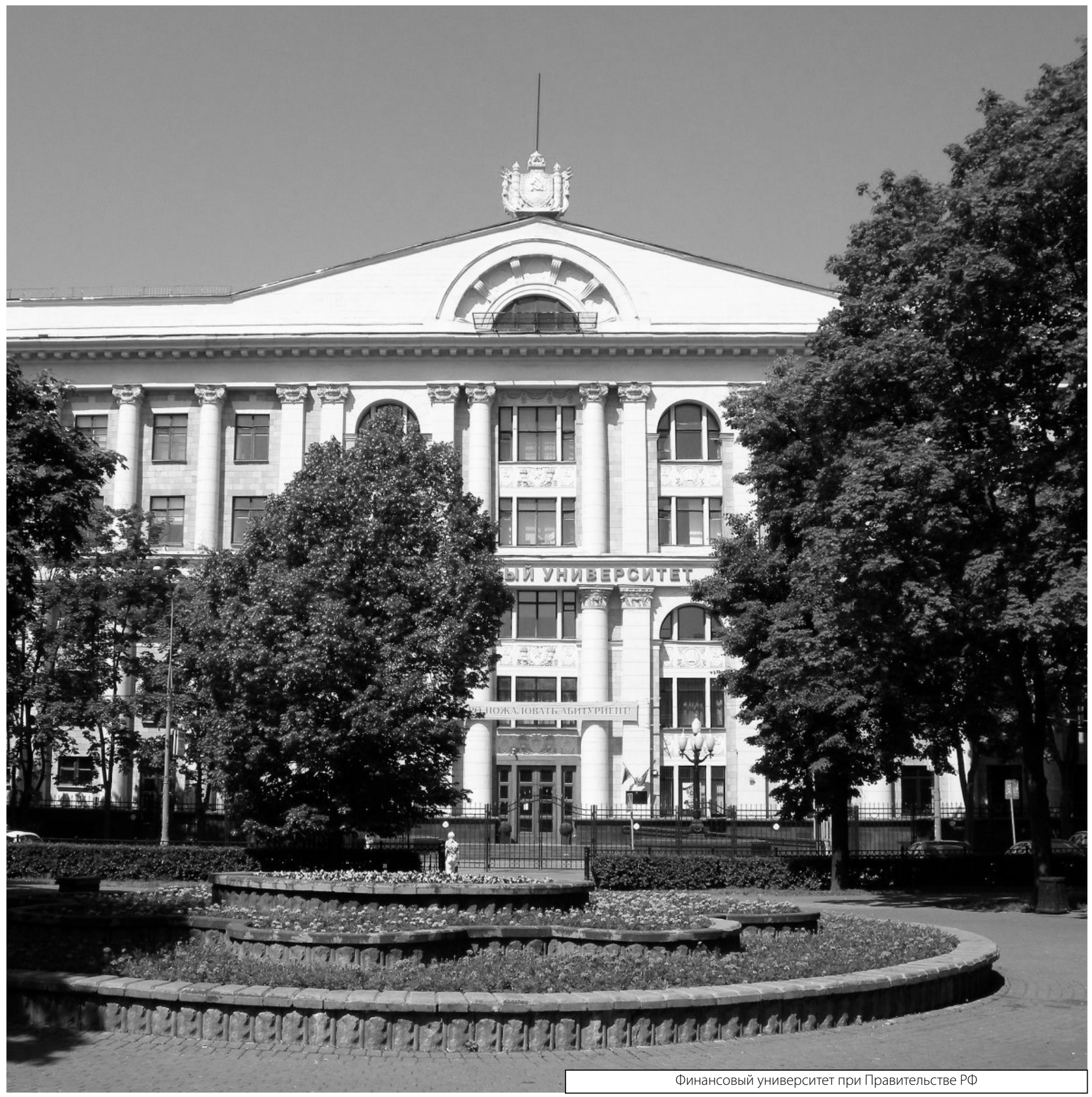

